EXPERIMENTAL STUDY

\title{
Norethisterone enanthate has neither a direct effect on the testis nor on the epididymis: a study in adult male cynomolgus monkeys (Macaca fascicularis)
}

Aris Junaidi, C Marc Luetjens, Joachim Wistuba, Axel Kamischke, Ching-Hei Yeung, Manuela Simoni and Eberhard Nieschlag

Institute of Reproductive Medicine of the University, Domagkstr. 11, D-48149 Münster, Germany

(Correspondence should be addressed to E Nieschlag; Email:nieschl@uni-muenster.de)

A Junaidi is now at the Faculty of Veterinary Medicine, Gadjah Mada University, Jl. Olah Raga, Yogyakarta, Indonesia

\begin{abstract}
Objective: Norethisterone enanthate (NETE) is evaluated in trials of hormonal male contraception. It has been speculated that progestins may exert their contraceptive effects not only by suppressing gonadotropins but also by direct effects on male organs. NETE was given to monkeys in which endogenous gonadotropin secretion was suppressed by a gonadotropin releasing hormone $(\mathrm{GnRH})$ antagonist, and replaced by human follicle-stimulating hormone (FSH) and human chorionic gonadotropin (hCG). If NETE has a direct effect on spermatogenesis and/or epididymal function, some changes in testicular histology, sperm motility and/or morphology should occur soon after exposure to NETE. Methods: Fifteen adult intact male monkeys were grouped and treated for a 38-day period. Group I received GnRH antagonist, FSH, hCG and NETE while group II received a regime identical to group I without NETE and group III received only NETE and vehicle. Ejaculates, body weight, testicular biopsies and volume, and hormones were evaluated.

Results: There was a similar pattern of serum FSH and testosterone in groups I and II. Testicular volume and the proportion of tubuli exhibiting spermatids was significantly decreased in group III. There were no significant differences between group I and group II in any parameters measured. The forward progression of sperm was not affected by NETE treatment. The consistently low percentages of grade c sperm indicated no sign of hyperactivation. No changes in the gross morphology of the acrosome were detected.

Conclusions: Short-term NETE treatment has neither a direct effect on the testis nor on the epididymis in this nonhuman primate model and its contraceptive effects appear to be exerted exclusively through gonadotropin suppression.
\end{abstract}

European Journal of Endocrinology 152 655-661

\section{Introduction}

In current approaches to hormonal male contraception gestagens in combination with testosterone are used (for review see 1). Administration of gestagens results in inhibition of gonadotropins and thereby in suppression of testosterone production and spermatogenesis. It is generally assumed that the effects of gestagens are mediated by the progesterone receptor in the hypothalamo-pituitary system, but it is unclear whether local effects in the genital tract also play a role.

Neither the expression pattern nor the cellular role of the genomic progesterone receptor (PR) in men are fully known (2-4). The PR has been demonstrated in the chicken testis and in the testis of patients with testicular feminization (5). As shown by reverse transcriptase polymerase chain reaction (RT-PCR), PR was expressed in the testis as well as in the prostate of the macaque monkey (Macaca fascicularis) (6). In preliminary experiments, we could localise the PR in the primate testis (the expression was restricted to a few peritubular cell nuclei) and in the epididymis of men and cynomolgus as well as marmoset monkeys (7). However, the function of the PR expression in the male genital tract remains unclear.

Norethisterone enanthate (NETE) is used in male contraceptive trials and has been shown to be more effective than other gestagens. In men, a single injection of $200 \mathrm{mg}$ NETE quickly led to profound and significant suppression of serum luteinizing hormone (LH), follicle-stimulating hormone (FSH), testosterone 
and sex hormone binding globulin (SHBG) and rapid suppression of spermatogenesis (8). It was speculated that NETE might result in better suppression of spermatogenesis due to an additional direct effect on the testis $(8,9)$. In rats it was shown that unilateral NETE implants in the epididymal fat pad led to drastic reduction of testicular size and weight as well as sperm production at the ipsilateral site, whereas the contralateral testis was not affected (10). It has been postulated that the occurrence of dead spermatozoa in the ductus deferens could also be due to the binding of NETE to the epididymal spermatozoa, thereby affecting sperm metabolism directly $(11-13)$. Based on these data and on the recent report that norethisterone is more potent and has a higher binding affinity to the PR than progesterone (14), we asked whether NETE has any direct action on the testes and/or on the epididymis in the primate.

To address this issue, we performed a study in cynomolgus monkeys and investigated possible changes in testis histology, in sperm motility and/or morphology soon after short-term exposure to NETE. In this model, endogenous gonadotropin secretion was suppressed by a gonadotropin releasing hormone (GnRH) antagonist, and gonadotropins were replaced by injection of recombinant human FSH and human chorionic gonadotropin (hCG). We compared the effects of NETE plus $\mathrm{FSH} / \mathrm{hCG}$ on sperm motility and morphology in GnRH antagonist-treated monkeys with those given $\mathrm{GnRH}$ antagonist plus $\mathrm{FSH} / \mathrm{hCG}$, and those receiving NETE alone.

\section{Materials and methods}

\section{Experimental animals}

Fifteen adult intact male cynomolgus monkeys (Macaca fascicularis) from our colony were allocated to three groups matched by age and weight distribution (body weight $8.7 \pm 1.4 \mathrm{~kg}$; age $9.5 \pm 2.6$ years). All animals were kept individually in a temperature and humidity controlled room, with a $12 \mathrm{~h}$ light: $12 \mathrm{~h}$ darkness period. They were fed a standard monkey pellet food supplemented with fresh fruit. Water was available ad libitum. For all interventions, monkeys were sedated by i.m. injection of ketamine hydrochloride (8-10 $\mathrm{mg} / \mathrm{kg}$ Ketavet; Parke-Davis, München, Germany) as previously described (15). All experiments were performed in accordance with the German Law for Care and Use of Laboratory Animals (Licence number: G67/2001).

Baseline values of body weight, testicular volume, serum testosterone and semen analysis (ejaculate weight, sperm count, sperm motility, sperm morphology) were determined. The investigators were blinded to the experimental status of the animals. In addition, at study day 0 and on the last study day (day 38) testicular biopsies were performed as previously described (16).

The study protocol is shown in Fig. 1. Group I was treated with daily s.c. injections of $450 \mu \mathrm{g} / \mathrm{kg} \mathrm{GnRH}$ antagonist (Cetrorelix; Asta Medica, Frankfurt, Germany) for the first 10 days, then the dose was reduced to $200 \mu \mathrm{g} / \mathrm{kg}$ for the rest of the study following the principle of high loading and low maintenance dose (17). This group also received daily s.c. injections of $5 \mathrm{IU} / \mathrm{kg}$ per body weight recombinant human $\mathrm{FSH}$ (Gonal-F; Serono, Unterschleissheim, Germany) and s.c. injections of $250 \mathrm{IU}$ hCG (Ovitrelle; Serono) every alternate day. On day 14 the FSH dosage was reduced to 1 injection $(5 \mathrm{IU} / \mathrm{kg}$ ) every alternate day and the dosage of hCG was reduced to 25 IU every alternate day until the end of the study. NETE $(70 \mathrm{mg}$ ) (Noristerat; Schering, Berlin, Germany) was given i.m. on day 0 and on day 21. Group II was treated as group I except that NETE was omitted. Group III was treated with i.m. injection of $70 \mathrm{mg}$ NETE on day 0 and on day 21 plus vehicle $(0.9 \%$ saline daily).

\section{Hormone assays}

Blood samples were collected by venipuncture of the saphenous vein, twice for baseline and afterwards weekly until the end of the study. Additional blood samples were taken on days 3,17, 23 and 24. Blood was allowed to clot overnight at $4^{\circ} \mathrm{C}$, after which the serum was separated and stored at $-20^{\circ} \mathrm{C}$ until analysis. Testosterone was assayed by an established RIA (18). Sensitivity of the assay was $0.68 \mathrm{nmol} / \mathrm{l}$ and intra- and interassay coefficients of variation values were $6.1 \%$ and $10.3 \%$ respectively. Human FSH was measured by immunofluorimetric assay using the Autodelfia equipment (Perkin Elmer, Freiburg, Germany). The sensitivity of the FSH assay was $0.5 \mathrm{U} / \mathrm{l}$ with intra- and interassay coefficients of variation of 4.2 and $6.5 \%$ respectively.

\section{Testis volume}

Testis volume was determined as previously described by measuring the length and width of the testis using Vernier callipers (16). The formula for an ellipsoid was used to estimate testicular volume.

\section{Semen analysis}

Ejaculates were obtained at weekly intervals by transrectal electroejaculation. Sperm counts were expressed per total ejaculate (exudates plus coagulum). Sperm morphology (Papanicolaou staining) and sperm motility were evaluated according to the World Health Organisation (WHO) Manual (19). 
(A)
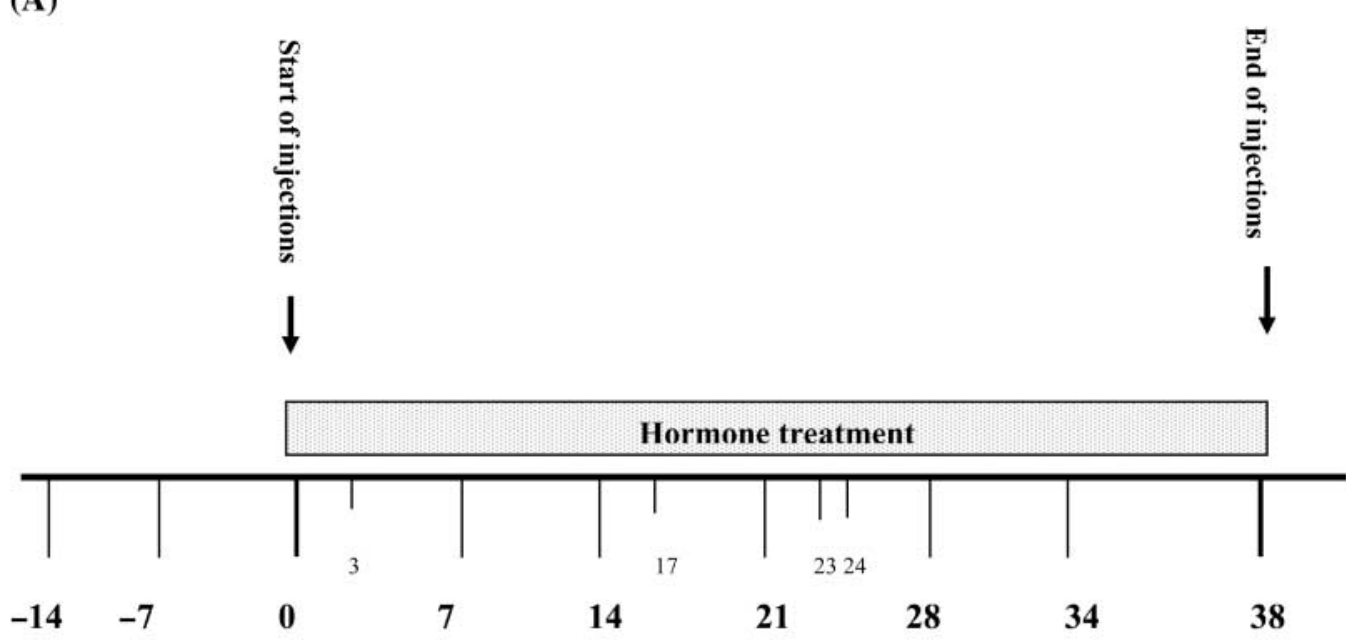

Study days

(B)

\begin{tabular}{|c|l|l|}
\hline Groups & \multicolumn{1}{|c|}{$\begin{array}{c}\text { Hormone treatment } \\
\text { Parameters measured } \\
\text { in all groups }\end{array}$} \\
\hline I & GnRH antagonist, FSH, hCG and NETE & Body weight, blood samples, testicular \\
II & GnRH antagonist, FSH and hCG & volume and semen analyses. Testicular \\
\hline III & NETE and vehicle & Additional blood samples were taken \\
& & on day $3,17,23$ and 24. \\
\hline
\end{tabular}

Figure 1 (A) Schematic representation of the experimental protocol. (B) Hormone treatment in the different groups and parameters measured. GnRH, gonadotropin releasing hormone; FSH, follicle-stimulating hormone; hCG, human chorionic gonadotrophin; NETE, norethisterone enanthate.

\section{Testicular histology}

Testicular biopsies were performed on day 0 and day 38. Tissue was fixed in Bouin's solution, embedded in paraffin and cut to $3 \mu \mathrm{m}$ sections for light microscopical analysis as described previously (16). Sections were stained with periodic acid Schiff's base and hematoxylin and the most advanced germ cell types were evaluated in all tubules.

\section{Statistics}

For statistical comparison, $t$-test or ANOVA followed by Tukey's test were performed. $P<0.05$ was considered to be significant. All analyses were performed using the statistical software GraphPadPrism for Windows version 3.0 (GraphPad Software Inc., San Diego, CA, USA). In general, results are given as means \pm S.E.M.

\section{Results}

\section{Body weight and testes volume}

During the treatment period no significant changes in bodyweight were observed between the three treatment groups. In group III there was a clear decrease in testicular volume which became significant on days 34 and 38 compared with groups I and II (Fig. 2A). In groups I and II no decrease in testicular volume was seen, but rather a tendency for a slight increase in volume.

\section{Hormones}

The injections every second day of hCG at the dose of 250 IU in groups I and II resulted in high serum testosterone levels starting on day 3 and these reached a maximum on day 7 in group I $(180.5 \pm 27.6 \mathrm{nmol} / \mathrm{l})$ and on day 14 in group II $(238.5 \pm 74.6 \mathrm{nmol} / \mathrm{l})$ 


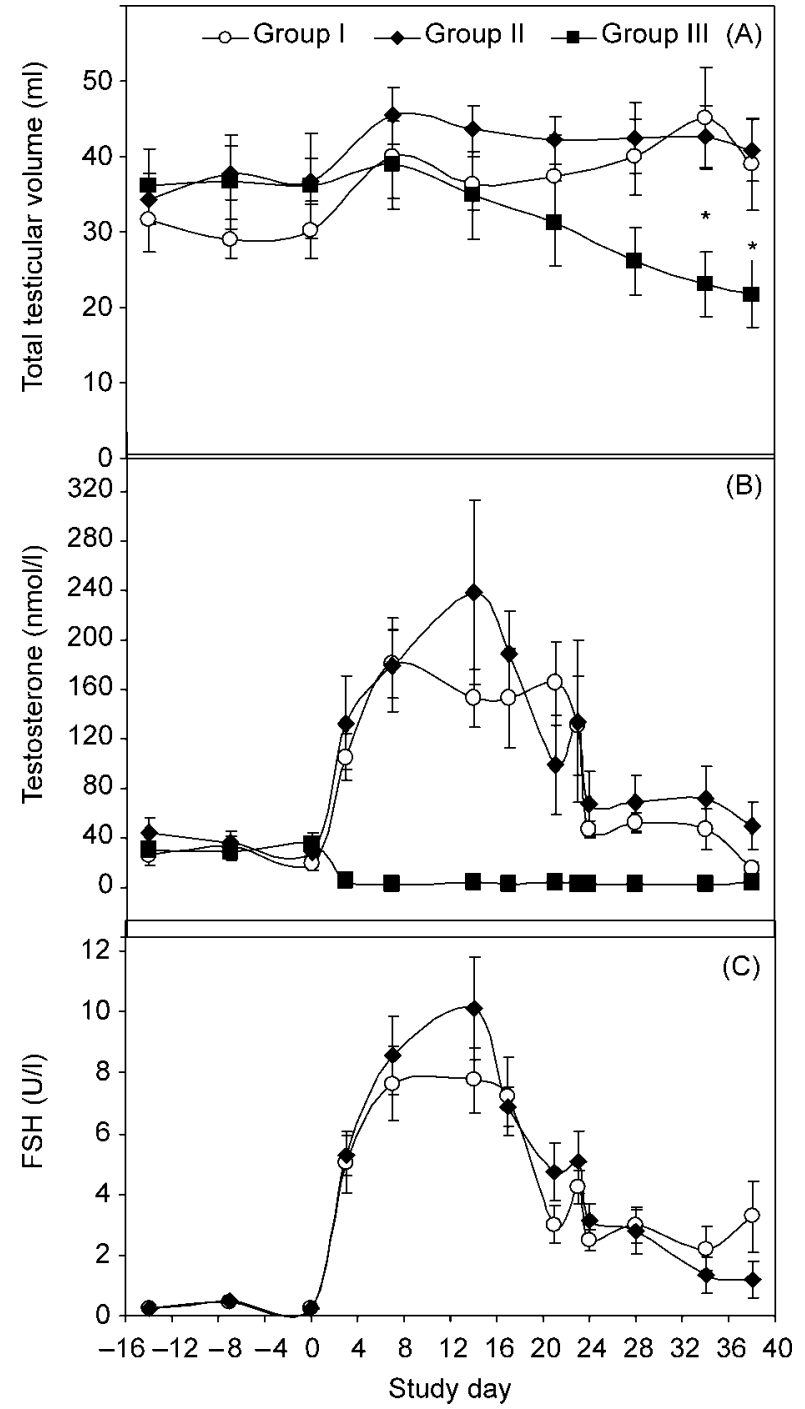

Figure 2 (A) Comparison of testicular volume between groups. Asterisks denote significant differences $(P<0.05)$ between group I and group II. (B) Comparison of serum testosterone concentrations between groups. (C) Comparison of serum human FSH concentrations between groups. In group III, FSH concentrations were below the detection level. Data are presented as means \pm S.E.M.

(Fig. 2B). The peak values were nearly 10-fold higher compared with baseline. FSH levels progressively increased as well (Fig. 2C). From day 14 on FSH was injected every second day and the dose of hCG was reduced to $25 \mathrm{IU} /$ injection. After this reduction, testosterone levels returned to the normal range and serum FSH levels were comparable to those expected in intact monkeys (20).

\section{Semen parameters}

Average sperm counts did not change during the study period of 38 days (Table 1, Fig. 3A). After the study end, sperm counts in group III decreased significantly $\left(783 \times 10^{6}\right.$ vs $\left.124 \times 10^{6}\right)$. Within the control group (group II), sperm motility (WHO a $+b$ and WHO c) remained unchanged (Fig. 3B). There was no significant difference in the sperm morphology between groups (Table 2).

\section{Testicular histology}

Results of testicular histology are shown in Table 3. No significant percentage differences were found among tubuli containing elongated spermatids within or between groups I and II whereas there was a significant difference in group III (Table 3). The proportion of elongated and round spermatids remained stable in group I and group II. In group III, the proportion of elongated spermatids declined from $79 \pm 5 \%$ to $55 \pm 5 \%$ and the round spermatids from $11 \pm 1 \%$ to $7 \pm 1 \%$. The proportion of tubuli containing spermatogenesis up to the spermatocyte level in group III was increased compared with the baseline $(16 \pm 2 \%$ vs $10 \pm 2 \%$ ) and the proportion restricted to the spermatogonia stage was significantly increased compared with the baseline $(22 \pm 4 \%$ vs $0 \%)$ and in both control groups $(22 \pm 4 \%$ vs $3 \pm 1 \%$, Table 3$)$.

\section{Discussion}

The goal of our study was to examine whether NETE has rapid effects on sperm parameters through direct action on the testes and/or on the epididymis in the macaque monkey. To this end, since NETE suppresses gonadotropins, it was administered to male monkeys in which endogenous gonadotropin secretion was suppressed by a GnRH antagonist, and replaced by injection of recombinant FSH and hCG. A similar approach to the study of feedback mechanisms has been reported recently using a 'testicular clamp' in which endogenous gonadotropin secretion was abolished with a GnRH antagonist, and the gonadotropin was replaced by infusion of recombinant human FSH and LH (21).

Table 1 Ejaculate weight $(\mathrm{g})$ of the monkeys in the three groups over time. Results are expressed as means \pm S.E.M.

\begin{tabular}{lccccccc}
\hline Group & Mean baseline & Day 7 & Day 14 & Day 21 & Day 28 & Day 34 & Day 38 \\
\hline I & $1.28 \pm 0.46$ & $0.64 \pm 0.46$ & $0.49 \pm 0.23$ & $1.34 \pm 1.15$ & $1.34 \pm 1.15$ & $1.34 \pm 1.15$ & $1.34 \pm 1.15$ \\
II & $1.69 \pm 0.55$ & $0.86 \pm 0.45$ & $1.65 \pm 1.35$ & $1.78 \pm 1.56$ & $1.78 \pm 1.56$ & $1.78 \pm 1.56$ & $1.78 \pm 1.56$ \\
III & $4.65 \pm 0.76$ & $5.74 \pm 4.28$ & $2.64 \pm 1.26$ & $4.68 \pm 3.06$ & $4.68 \pm 3.06$ & $4.68 \pm 3.06$ & $4.68 \pm 3.06$ \\
\hline
\end{tabular}




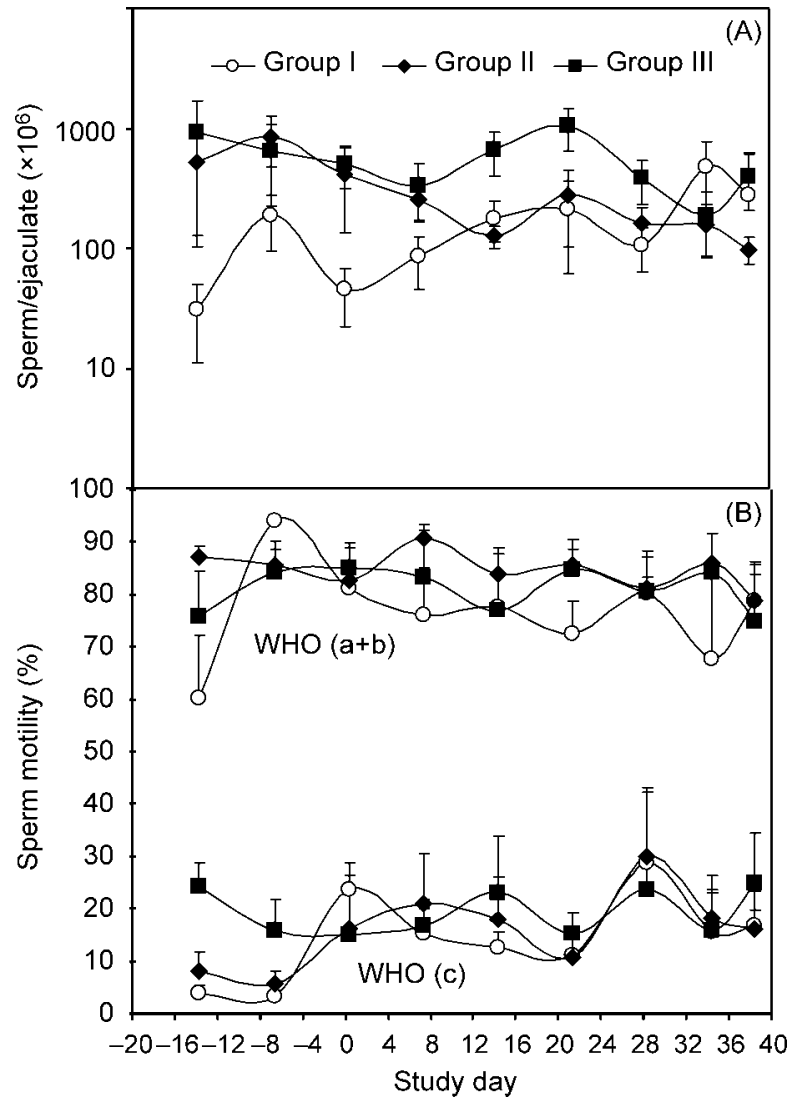

Figure $3(A)$ Comparison of sperm counts between groups. (B) Comparison of sperm motility WHO $(\mathrm{a}+\mathrm{b})$ and $\mathrm{WHO}(\mathrm{c})$ between groups. Data are presented as means \pm S.E.M.

The efficacy of Cetrorelix in suppressing endogenous gonadotropin secretion in cynomolgus monkeys has been established previously (16). The effect of administration of FSH on spermatogenesis in the GnRH antagonist-suppressed nonhuman primate model (22) and the combined treatment using FSH and hCG in the primate have also been reported previously (23). The initial doses were based on previous findings, showing that a dose of FSH between 30 and $80 \mathrm{IU} /$ day and of hCG of $250 \mathrm{IU} /$ alternate day maintained gonadal functions in juvenile and adult cynomolgus monkeys $(23,24)$. Unexpectedly, this resulted in supraphysiological serum FSH and testosterone levels, thus the doses of FSH and hCG were reduced. This resulted in normal circulatory levels of FSH and testosterone, active spermatogenesis, normal sperm morphology and motility and testis volume during the study period in the control group (group II). Therefore, it is justified to conclude that endogenous gonadotropin secretion was maintained during Cetrorelix treatment both in group I and in group II.

The efficacy of NETE as a suppressor of pituitary LH is well established $(9,25)$. NETE has typical progestational actions, and interacts preferentially with the PR and to a lesser extent with the androgen receptor
(26). NETE is hydrolyzed to release the active compound norethisterone, which can be $5 \alpha$-reduced to $5 \alpha$-norethisterone and aromatized to ethinyl estradiol (27). During contraceptive trials in men NETE led to strong, rapid and sustained suppression of serum FSH and testosterone values (9). Our findings in the macaques confirm this effect of NETE alone. However, sperm parameters remained unchanged throughout the experimental period, possibly due to its short duration. Prolonged treatment is required for alterations in sperm parameters to become manifest, as evidenced by an additional sample taken at study day 71 , when monkeys of group III showed a significant decrease in sperm counts (data not shown). This finding is consistent with the previous report showing that administration of NETE in male bonnet monkeys resulted in azoospermia in all monkeys within 60 to 150 days (28). Furthermore, in the present study histology showed that the proportion of tubuli exhibiting elongated and round spermatids was significantly decreased and the proportion of tubuli containing spermatogenesis up to the spermatocyte level and tubuli containing spermatogenesis up to spermatogonia level were increased, demonstrating a strong decrease in germ cells having the ability to differentiate and undergo meiosis. However, when NETE was administered to the animals treated additionally with gonadotropins, no changes were seen in any of the parameters, confirming that the NETE effect on histological parameters observed in group III was mediated by gonadotropin suppression.

Very few data on PR expression in the male are available. By RT-PCR, PR was found to be highly expressed in the testis and to some extent in the epididymis of cynomolgus monkeys (6), but was not localized in certain cell types. There are reports of PR on human sperm plasma membrane $(29,30)$. The effects of progesterone on sperm capacitation are well established, particularly in human ejaculated sperm (31). Its physiological significance is presumably realised in the female tract when sperm encounter the cumulus oophorus and the oocyte in the Fallopian tube. Despite the presence of the PR in the primate epididymis the role of progesterone in the maturation of spermatozoa in the male tract is obscure (6). In the present study, forward progression, the functional sperm parameter that changes most during maturation in the epididymis (32), was not affected by NETE treatment. The consistently low percentages of grade $\mathrm{c}$ sperm in all groups indicated no sign of NETE-induced hyperactivation. No changes in the acrosome gross morphology were detected by Papanicolaou staining and phase-contrast microscopy among the different treatment groups, as shown by the absence of abnormal heads.

In conclusion, the present study demonstrates that in the adult male monkey in which the gonadotropic stimulus to the testis is maintained, NETE does not 
Table 2 Sperm morphology of the monkeys in the three groups over time. Results are expressed as means \pm S.E.M.

\begin{tabular}{|c|c|c|c|c|}
\hline Day of treatment & Head defects & Midpiece defects & Tail defects & Normal \\
\hline \multicolumn{5}{|l|}{ Group I } \\
\hline-14 & 0 & 0 & $11.2 \pm 5.0$ & $88.8 \pm 39.7$ \\
\hline-7 & $0.4 \pm 0.2$ & $0.4 \pm 0.2$ & $7.2 \pm 3.2$ & $92.2 \pm 41.2$ \\
\hline 0 & $0.4 \pm 0.2$ & $0.2 \pm 0.1$ & $7.2 \pm 3.2$ & $92.4 \pm 41.3$ \\
\hline 7 & 0 & $2.6 \pm 1.2$ & $18.5 \pm 8.3$ & $78.3 \pm 35$ \\
\hline 14 & 0 & $0.8 \pm 0.4$ & $15.3 \pm 6.8$ & $83.8 \pm 37.5$ \\
\hline 21 & $0.2 \pm 0.1$ & $0.6 \pm 0.3$ & $37.0 \pm 16.6$ & $52.8 \pm 23.6$ \\
\hline 28 & $0.2 \pm 0.1$ & 0 & $28.0 \pm 12.5$ & $67.3 \pm 31$ \\
\hline 34 & 0 & $1.4 \pm 0.6$ & $24.3 \pm 10.9$ & $73.3 \pm 32.4$ \\
\hline 38 & $0.6 \pm 0.3$ & $1.0 \pm 0.5$ & $33.0 \pm 14.8$ & $65.4 \pm 29.3$ \\
\hline \multicolumn{5}{|l|}{ Group II } \\
\hline-14 & $0.4 \pm 0.2$ & $0.4 \pm 0.2$ & $14 \pm 6.3$ & $85.2 \pm 38.1$ \\
\hline-7 & 0 & $1 \pm 0.4$ & $8.6 \pm 3.8$ & $89.8 \pm 40.2$ \\
\hline 0 & 0 & $1.0 \pm 0.5$ & $8.6 \pm 3.9$ & $91.0 \pm 40.3$ \\
\hline 7 & $0.2 \pm 0.1$ & $1.8 \pm 0.8$ & $8.8 \pm 3.9$ & $89.2 \pm 39.9$ \\
\hline 14 & $0.2 \pm 0.1$ & $0.6 \pm 0.3$ & $14.6 \pm 6.5$ & $84.6 \pm 37.8$ \\
\hline 21 & $0.4 \pm 0.2$ & 0 & $5.0 \pm 2.2$ & $92.7 \pm 41.4$ \\
\hline 28 & 0 & $0.4 \pm 0.2$ & $10.3 \pm 4.6$ & $89.0 \pm 39.8$ \\
\hline 34 & $0.4 \pm 0.2$ & $0.8 \pm 0.4$ & $17.0 \pm 7.6$ & $81.8 \pm 36.6$ \\
\hline 38 & $0.4 \pm 0.2$ & $0.6 \pm 0.3$ & $10.0 \pm 4.5$ & $88.8 \pm 39.7$ \\
\hline \multicolumn{5}{|l|}{ Group III } \\
\hline-14 & $0.2 \pm 0.1$ & $0.4 \pm 0.2$ & $21.2 \pm 9.5$ & $78.4 \pm 35.1$ \\
\hline-7 & $0.6 \pm 0.3$ & $1.2 \pm 0.5$ & $8.6 \pm 3.8$ & $89.6 \pm 40.1$ \\
\hline 0 & 0 & $0.6 \pm 0.3$ & $19.8 \pm 8.8$ & $80.4 \pm 35.5$ \\
\hline 7 & $0.2 \pm 0.1$ & $6.2 \pm 2.8$ & $18.4 \pm 8.2$ & $75.2 \pm 33.6$ \\
\hline 14 & 0 & $6.8 \pm 3.1$ & $13.0 \pm 5.8$ & $76.3 \pm 33.69$ \\
\hline 21 & $0.2 \pm 0.1$ & $2.2 \pm 0.9$ & $24.5 \pm 10.9$ & $72.5 \pm 32.4$ \\
\hline 28 & $0.2 \pm 0.1$ & 0 & $38.8 \pm 17.4$ & $62.4 \pm 27$ \\
\hline 34 & 0 & $2.0 \pm 0.9$ & $30.4 \pm 13.6$ & $68.4 \pm 30.1$ \\
\hline 38 & $0.6 \pm 0.3$ & $2.4 \pm 1.1$ & $41.6 \pm 18.6$ & $55.4 \pm 24.8$ \\
\hline
\end{tabular}

Table 3 Testicular histology before and at the end of treatment. Results are expressed as means \pm S.E.M.

\begin{tabular}{|c|c|c|c|}
\hline Parameters & Group & Before treatment $(\%)$ & End of treatment $(\%)$ \\
\hline \multirow[t]{3}{*}{ Tubuli containing elongated spermatids } & I & $69 \pm 3$ & $72 \pm 4$ \\
\hline & II & $72 \pm 2$ & $74 \pm 4$ \\
\hline & III & $79 \pm 5$ & $55 \pm 5^{\star \star}+\dagger$ \\
\hline \multirow[t]{3}{*}{ Tubuli containing spermatogenesis up to the round spermatid level } & I & $15 \pm 1$ & $13 \pm 1$ \\
\hline & II & $19 \pm 2$ & $12 \pm 1$ \\
\hline & III & $11 \pm 1^{* *}$ & $7 \pm 1^{* \star \star} \dagger \dagger \dagger$ \\
\hline \multirow[t]{3}{*}{ Tubuli containing spermatogenesis up to the spermatocyte level } & I & $13 \pm 1$ & $12 \pm 1$ \\
\hline & II & $8 \pm 1$ & $11 \pm 1 \dagger \dagger$ \\
\hline & III & $10 \pm 2^{\star \star}$ & $16 \pm 2 \dagger$ \\
\hline \multirow{3}{*}{ Tubuli containing spermatogenesis up to the spermatogonia level } & I & $3 \pm 1$ & $3 \pm 1$ \\
\hline & II & $1 \pm 0$ & $3 \pm 1 \dagger \dagger$ \\
\hline & III & 0 *** & $22 \pm 4^{\star \star \star} † \dagger \dagger$ \\
\hline
\end{tabular}

*Significant difference between the groups within the time of observation; †significant difference within the group before and at the end of treatment. ${ }^{\star} * P<0.01,{ }^{* \star \star} P<0.001 . \dagger P<0.05, \dagger \dagger P<0.01, \dagger^{\dagger} \dagger P<0.001$

have a direct effect on the testis nor on the epididymis. The strong suppressive effect of NETE on primate spermatogenesis appears therefore to be due uniquely to its gonadotropin suppressive action.

\section{Acknowledgements}

Dr Aris Junaidi is the recipient of an Alexander von Humboldt Fellowship and a grant from the Alexander von Humboldt Foundation. We thank Dr W Bilger, Serono
Laboratories, Unterschleissheim, Germany for providing the recombinant human FSH and hCG. We are grateful to R Sandhowe-Klawerkamp, M Heuermann and G Stelke for their excellent technical assistance.

\section{References}

1 Nieschlag E, Zitzmann M \& Kamischke A. Use of progestins in male contraception. Steroids $2003 \mathbf{6 8} 965-972$.

2 Burgess HE \& Shousha S. An immunohistochemical study of the long-term effects of androgen administration on female-to-male

www.eje-online.org 
transsexual breast: a comparison with normal female breast and male breast showing gynaecomastia. Journal of Pathology 1993 $17037-43$.

3 Pacheco MM, Oshima CF, Lopes MP, Widman A, Franco EL \& Brentani MM. Steroid hormone receptors in male breast diseases. Anticancer Research 19866 1013-1017.

4 Pensler JM, Silverman BL, Sanghavi J, Goolsby C, Speck G, BrizioMolteni L \& Molteni A. Estrogen and progesterone receptors in gynecomastia. Plastic and Reconstructive Surgery $2000 \mathbf{1 0 6}$ 1011-1013.

5 Dube JY \& Tremblay RR. Search for progesterone receptors in testes from various animal species. Molecular and Cellular Endocrinology $19791639-44$.

6 Heikinheimo O, Mahony MC, Gordon K, Hsiu JG, Hodgen GD \& Gibbons WE. Estrogen and progesterone receptor mRNA are expressed in distinct pattern in male primate reproductive organs. Journal of Assisted Reproduction Genetics 199512 198-204.

7 Luetjens CM, Didolker A, Kliesch S, Jaibmann A, Böcker W, Nieschlag E \& Simoni M. Expression pattern of the nuclear progesterone receptor in men and male nonhuman primates. Andrologia 200436218.

8 Kamischke A, Plöger D, Venherm S, Von Eckardstein S, Von Eckardstein A \& Nieschlag E. Intramuscular testosterone undecanoate with or without oral levonorgestrel: a randomized placebo-controlled feasibility study for male contraception. Clinical Endocrinology 200053 43-52.

9 Kamischke A, Diebacker J \& Nieschlag E. Potential of norethisterone enanthate for male contraception: pharmacokinetics and suppression of pituitary and gonadal function. Clinical Endocrinology $200053351-358$.

10 Srivastava UK \& Malaviya B. Effect of chronic local administration of norethisterone enanthate on the testes of adult rat. Indian Journal of Physiology and Pharmacology 1980 24 49-55.

11 Hyne RV \& Boettcher B. The selective binding of steroids by human spermatozoa. Contraception 197715 163-174.

12 Hyne RV \& Boettcher B. Binding of steroids to human spermatozoa and its possible role in contraception. Fertility and Sterility $197830322-328$.

13 Hyne RV, Murdoch RN \& Boettcher B. The metabolism and motility of human spermatozoa in the presence of steroid hormones and synthetic progestagens. Journal of Reproduction and Fertility 197853 315-322.

14 Sitruk-Ware R. Pharmacological profile of progestins. Maturitas $200447277-283$.

15 Weinbauer GF, Limberger A, Behre HM \& Nieschlag E. Can testosterone alone maintain the gonadotrophin-releasing hormone antagonist-induced suppression of spermatogenesis in the nonhuman primate? Journal of Endocrinology 1994142 485-495.

16 Weinbauer GF, Schubert J, Yeung CH, Rosiepen G \& Nieschlag E. Gonadotrophin-releasing hormone antagonist arrests premeiotic germ cell proliferation but does not inhibit meiosis in the male monkey: a quantitative analysis using 5-bromodeoxyuridine and dual parameter flow cytometry. Journal of Endocrinology $199815623-34$.

17 Behre HM, Kliesch S, Puhse G, Reissmann T \& Nieschlag E. High loading and low maintenance doses of a gonadotropin-releasing hormone antagonist effectively suppress serum luteinizing hormone, follicle-stimulating hormone, and testosterone in normal men. Journal of Clinical Endocrinology and Metabolism $1997 \mathbf{8 2}$ 1403-1408.

18 Chandolia RK, Weinbauer GF, Simoni M, Behre HM \& Nieschlag E. Comparative effects of chronic administration of the non-steroidal antiandrogens flutamide and Casodex on the reproductive system of the adult male rat. Acta Endocrinologica 1991125 547-555.
19 World Health Organisation. WHO Laboratory Manual for the Examination of Human Semen and Sperm-Cervical Mucus Interaction, 4th edition. Cambridge: Cambridge University Press, 1999.

20 Narula A, Gu YQ, O’Donnell L, Stanton PG, Robertson DM, Mclachlan RI \& Bremner WJ. Variability in sperm suppression during testosterone administration to adult monkeys is related to follicle stimulating hormone suppression and not to intratesticular androgens. Journal of Clinical Endocrinology and Metabolism $2002873399-3406$.

21 Simorangkir DR, Ramaswamy S, Marshall GR \& Plant TM. In the adult male rhesus monkey (Macaca mulatta), unilateral orchidectomy in the face of unchanging gonadotropin stimulation results in partial compensation of testosterone secretion by the remaining testis. Endocrinology 2004145 5115-5120.

22 Weinbauer GF, Behre HM, Fingscheidt U \& Nieschlag E. Human follicle-stimulating hormone exerts a stimulatory effect on spermatogenesis, testicular size, and serum inhibin levels in the gonadotropin-releasing hormone antagonist-treated nonhuman primate (Macaca fascicularis). Endocrinology $1991 \quad 129$ $1831-1839$.

23 Schlatt S, Arslan M, Weinbauer GF, Behre HM \& Nieschlag E. Endocrine control of testicular somatic and premeiotic germ cell development in the immature testis of the primate Macaca mulatta. European Journal of Endocrinology 1995133 235-247.

24 Kamischke A, Kuhlmann M, Weinbauer GF, Luetjens M, Yeung $\mathrm{CH}$, Kronholz HL \& Nieschlag E. Gonadal protection from radiation by $\mathrm{GnRH}$ antagonist or recombinant human FSH: a controlled trial in a male nonhuman primate (Macaca fascicularis). Journal of Endocrinology 2003 179 183-194.

25 Koetsawang S. Once-a-month injectable contraceptives: efficacy and reasons for discontinuation. Contraception $1994 \mathbf{4 9}$ 387-398.

26 Chavez BA, Vilchis F, Perez AE, Garcia GA, Grillasca I \& PerezPalacios G. Stereospecificity of the intracellular binding of norethisterone and its A-ring reduced metabolites. Journal of Steroid Biochemistry and Molecular Biology 198522 121-126.

27 Kamischke A \& Nieschlag E. Progress towards hormonal male contraception. Trends in Pharmacological Sciences 200425 $49-57$.

28 Shetty G, Krishnamurthy H, Krishnamurthy HN, Ramachandra SG \& Moudgal NR. Use of norethisterone and estradiol in mini doses as a contraceptive in the male. Efficacy studies in the adult male bonnet monkey (Macaca radiata). Contraception $1997 \mathbf{5 6}$ 257-265.

29 Luconi M, Bonaccorsi L, Bini L, Liberatori S, Pallini V, Forti G \& Baldi E. Characterization of membrane nongenomic receptors for progesterone in human spermatozoa. Steroids $2002 \mathbf{6 7}$ 505-509.

30 Sabeur K, Edwards DP \& Meizel S. Human sperm plasma membrane progesterone receptor(s) and the acrosome reaction. Biology of Reproduction 1996 54 993-1001.

31 Calogero AE, Burrello N, Barone N, Palermo I, Grasso U \& D'Agata R. Effects of progesterone on sperm function: mechanisms of action. Human Reproduction 200015 (Suppl 1) 28-45.

32 Yeung $\mathrm{CH}$, Cooper TG \& Weinbauer GF. Maturation of monkey spermatozoa in the epididymis with respect to their ability to undergo the acrosome reaction. Journal of Andrology $1996 \mathbf{1 7}$ 427-432.

Received 13 October 2004

Accepted 22 December 2004 